\title{
Visualizing soil deformation in the undergraduate classroom using Digital Image Correlation (DIC)
}

\section{Dr. Michael Patrick McGuire P.E., Lafayette College}

Dr. Michael P. McGuire is an Assistant Professor in the Department of Civil and Environmental Engineering at Lafayette College in Easton, Pennsylvania. He received his B.S. in Civil Engineering from the University of Pennsylvania, M.S. and Ph.D. in Civil Engineering from Virginia Tech, and is a registered Professional Engineer in the Commonwealth of Virginia. Dr. McGuire teaches courses in geotechnical engineering, sustainability, and engineering design as well as advises undergraduate students participating in research projects and independent studies. His research interests include column-supported embankments, mechanically-stabilized earth walls, and flood protection infrastructure. He is also interested in the application of terrestrial LIDAR to performance monitoring of geotechnical structures.

Dr. Jeffrey David Helm, Lafayette College 


\section{Visualizing soil deformation in the undergraduate classroom using Digital Image Correlation (DIC)}

\section{Introduction}

It is typical for an introductory undergraduate course in geotechnical engineering to expose students to the subjects of lateral earth pressure and bearing capacity. An understanding of bearing capacity and lateral earth pressure is essential for the design of foundations, retaining walls, and anchoring systems. This paper describes ongoing work to develop equipment, software, and hands-on teaching activities that apply Digital Image Correlation (DIC) to enhance a student's first exposure to lateral earth pressure and bearing capacity. The approach described herein enables students to observe the relationship between load acting on the soil and structural displacement for conditions similar to those of a loaded footing, retaining wall, or embedded ground anchor. The DIC system allows the students to see the magnitude, direction, and distribution of soil displacements. The ability to simultaneously observe load, structural displacement, and soil displacement provides a powerful teaching tool to show the connection between geotechnical analyses performed to estimate failure loads with analyses used to estimate deformations.

In addition to discussing the proposed methodology and initial results, this paper provides relevant background information related to DIC, lateral earth pressure, and bearing capacity. A literature review was performed to compile previous efforts to use DIC as an educational tool in undergraduate engineering education. Proposed teaching activities are briefly outlined. A followup paper will discuss the proposed teaching activities in detail and the impacts on student learning

\section{Motivation}

In conventional geotechnical practice, established theories for bearing capacity and lateral earth pressure are used to determine the limiting loads between a soil and a structure. These theories do not address the relationship between load and displacement. Separate analytical methods are used for the purpose of estimating soil displacements, such as settlement. This framework, which decouples consideration of failure load and deformation, is typically applied to the teaching of geotechnical engineering at the undergraduate level. As a result, it is difficult for students to realize that failure load analyses and deformation analyses are separated for convenience rather than some requirement of mechanics. Constitutive stress-strain relationships can be skillfully applied in a numerical model developed using the finite element method or finite difference method to reasonably predict the behavior of soil and soil-structure interaction ${ }^{1}$; however, a student needs to believe what they are seeing is "true" in order for the teaching tool to be effective. Soil behavior previously observed in the field or in the laboratory can be expressed in a variety of ways including charts, as shown in Figure 1, and photographs, as shown in Figure 2. These ways of illustrating soil behavior can help student appraise the reasonableness of theories and analytical solutions, but they remain substitutes for firsthand experience. Therefore, there is a need for an approach that provides students immediate and tangible evidence of the 
relationships between load and displacement in soils. The authors believe that Digital Image Correlation (DIC) provides a valuable tool that enables students to visualize soil displacements simultaneously with structural displacements. A goal of this approach is to create an experience that "sticks" with the students as they learn the theories and analytical approaches used to estimate failure loads and soil displacements. It is hoped that students will better appreciate the ingenuity that went into the development of the traditional analytical methods as well as the limitations of the underlying assumptions.

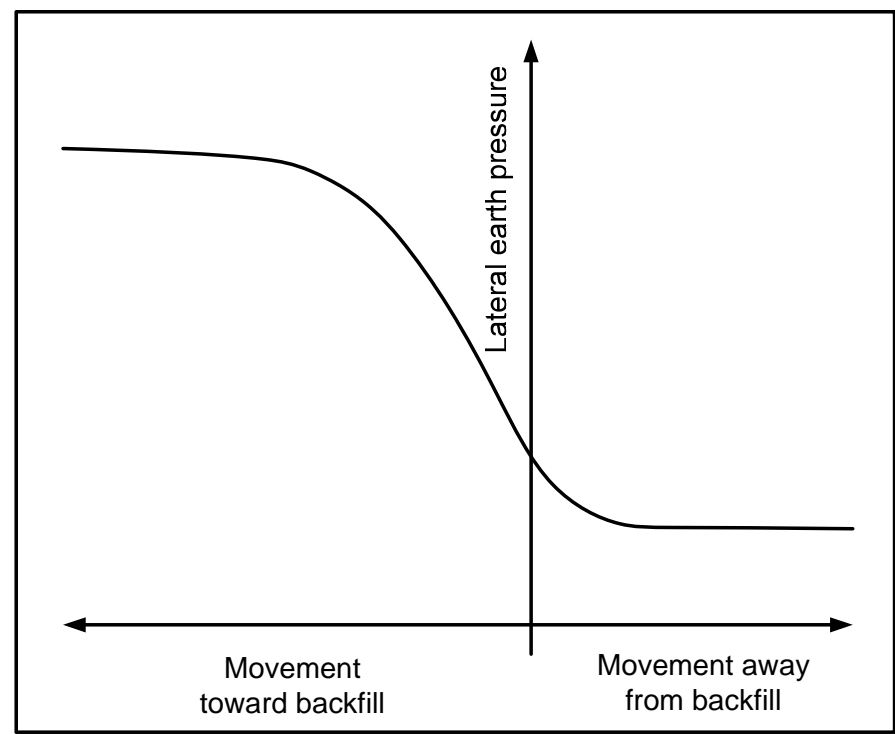

Figure 1: Relationship between wall movement and earth pressure (adapted) ${ }^{2}$
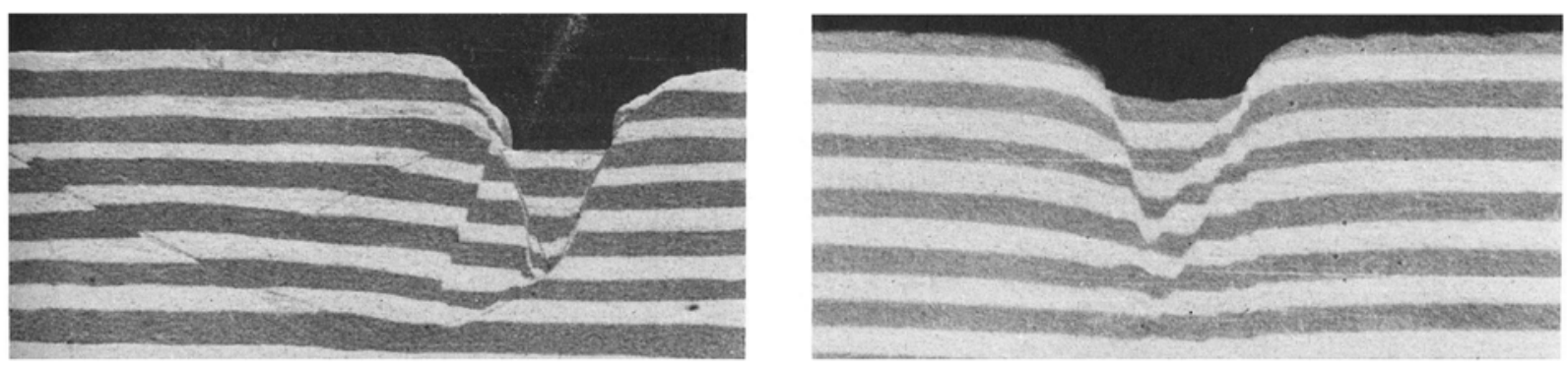

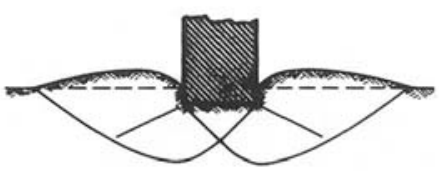

(a) General shear
产

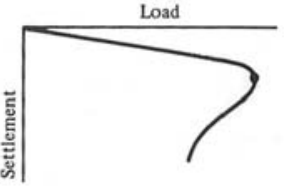

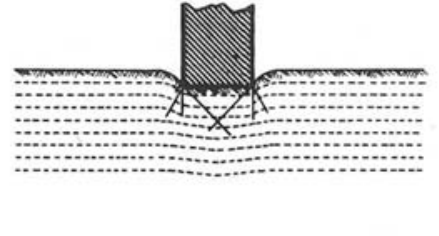

(b) Punching shear

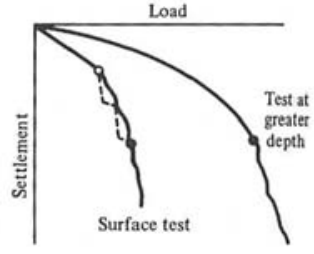

Figure 2: Soil deformation and relationship between bearing pressure and settlement observed in the laboratory ${ }^{3}$ 


\section{Overview of Digital Image Correlation (DIC)}

Digital Image Correlation (DIC) refers to a class of non-contact methods used to perform fullfield displacement measurement by comparing the position of small regions, called subsets, in a reference image to their corresponding location in a deformed image of the same subject taken at different times ${ }^{4}$. The correspondence is established by matching the gray-level pattern from the initial subset to the pattern at the deformed location in the other image. The historical development of DIC can be traced back to the measurement of changing ground conditions from aerial reconnaissance photography in the 1950s-60s and the use of X-ray tomography to measure strain fields in sand in the $1960 \mathrm{~s}^{4,5}$. The evolution of digital imaging technology and computerbased image processing through the 1970s-80s allowed the development of practical DIC systems. DIC was typically used by the solid mechanics community. During the same time frame a similar method, Particle Image Velocimetry (PIV), was developed to measure seeded fluid flows and was used by the fluid mechanics community. The two methods are both based on pattern correlation and the terms DIC and PIV are sometimes used synonymously.

DIC can be performed to measure in-plane displacements on a two-dimensional surface (2DDIC), in-plane and out-of-plane displacement on a three-dimensional surface (3D-DIC), and true three-dimensional displacements within a volume (V-DIC $)^{6}$. The system described in this paper employs 2D-DIC to measure the planer soil movements. DIC uses the correspondence between patterns in the reference image and the deformed image to measure the in-plane displacements of the test specimen. To accomplish this, the measured surface must have a contrasting pattern of suitable scale for the matching algorithm. Spray paint is often used to create the speckle pattern on test specimens composed of continuous solid materials (e.g. steel). For the application described in this paper, the speckle pattern was created by mixing a lightly-colored sand with a black coal slag blasting abrasive to form a speckled pattern. During an experiment, the test specimen is imaged at intervals defined by time, load, or displacement.

During image processing, the images are divided into small subsets of pixels. Each subset in the reference image is selected and the pattern is mapped to the deformed image, while allowing translation, rotation, and constant strain within the subset. For black and white images, the gray level for each pixel in the reference subset is compared to the gray level at the mapped location in the deformed subset using a cross-correlation error function. To increase the accuracy of the mapping the gray levels in the deformed image interpolated to produce values at a sub-pixel level. The process of mapping and error checking is iterated by changing the mapping parameters using standard Newton-Raphson-based optimization techniques until error is minimized. A full-field map of the surface displacements is produced once all of the subsets in the reference image have been mapped with minimum error to the deformed image. The size of the subsets, measured in pixels, is often specified in the program by the user. The number of pixels between successive subsets, known as the step size, is also often a user-specified parameter. When the step size is smaller than the subset size, there is overlap between successive subsets.

Figure 3 shows that there has been a significant upward trend in the number of publications that describe the use of DIC in civil engineering research projects, particularly in the past five years. This figure was generated by tracking the number of results sorted by publication year from a 
search of the ASCE Civil Engineering Database (ASCE CEDB) using the search string "digital image correlation." Suleiman et al. (2014) ${ }^{7}$ lists a number of studies in geotechnical engineering that have applied DIC as a research tool. Table 1 provides a non-exhaustive list of additional studies that have used some form of DIC to measure soil deformation. The research topics listed are broad-ranging; however at present, there is an emphasis on laboratory evaluation of soil behavior and reduced-scale modeling of geotechnical structures.

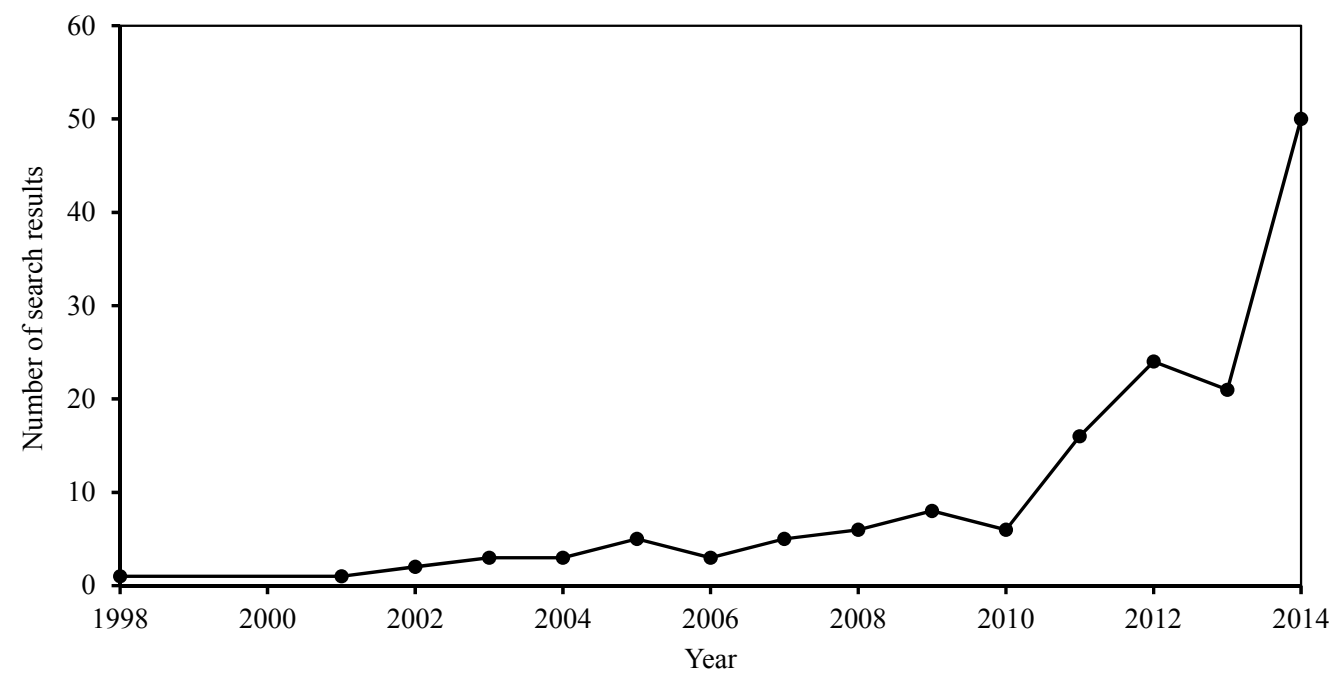

Figure 3: Number of results returned per year by searching "digital image correlation" in the ASCE CEDB

Table 1: Some published research using DIC or PIV to measure soil deformation

\begin{tabular}{|l|l|l|}
\hline Publication & \multicolumn{1}{|c|}{ Research topic } & $\begin{array}{l}\text { Type of image } \\
\text { analysis }\end{array}$ \\
\hline White et al. $(2003)^{8}$ & Application of PIV to geomechanics & 2D-PIV \\
\hline Bhandari et al. $(2012)^{9}$ & Triaxial testing of sand & 3D DIC \\
\hline Hall et al. $(2010)^{5}$ & Triaxial testing of sand & V-DIC \\
\hline Vitone et al. $(2013)^{10}$ & Plane strain testing of fissured clay & 2D-DIC \\
\hline $\begin{array}{l}\text { DeJong and Westgate } \\
(2009)^{11}\end{array}$ & $\begin{array}{l}\text { Interface direct shear testing of sand and } \\
\text { steel }\end{array}$ & 2D-PIV \\
\hline Divya et al. $(2014)^{12}$ & Tension testing of fiber-reinforced silts & 2D-DIC \\
\hline $\begin{array}{l}\text { Lesniewska and Wood } \\
(2009)^{13}\end{array}$ & $\begin{array}{l}\text { Soil behavior behind model retaining } \\
\text { wall }\end{array}$ & $\begin{array}{l}\text { 2D-PIV using } \\
\text { transparent soil }\end{array}$ \\
\hline Suleiman et al. $(2014)^{7}$ & Laterally-loaded piles & 3D-DIC \\
\hline Tian et al. $(2013)^{14}$ & Anchors for offshore structures & 2D-PIV \\
\hline $\begin{array}{l}\text { Ahmed and Iskander } \\
(2011)^{15}\end{array}$ & Tunneling-induced ground movement & $\begin{array}{l}\text { V-DIC using } \\
\text { transparent soil }\end{array}$ \\
\hline Daehne and Corsini $(2013)^{16}$ & Landslide movements & LIDAR 3D-DIC \\
\hline
\end{tabular}




\section{Significance of DIC as an educational tool}

Table 2 provides a list of the publications identified that describe the use of DIC and PIV in engineering education. Inspection of Table 2 suggests that the vast majority of the accounts focus on teaching fluid mechanics ( 8 out of 11 ), with two accounts describing application to teaching solid mechanics and one account of an application of DIC applied to teaching soil mechanics. It is interesting to note that almost all of the reported educational uses were in mechanical engineering; all were for undergraduates, and almost all fluid 2D-PIV. The few solid and soil applications are 2D-DIC.

Table 2: Published applications of DIC and PIV to engineering education

\begin{tabular}{|l|c|}
\hline Publication & Application \\
\hline Papadopoulos $(2003)^{17}$ & Fluid Mechanics \\
\hline Ring and Lemley $(2014)^{18}$ & Fluid Mechanics \\
\hline Brower $(2011)^{19}$ & Fluid Mechanics \\
\hline Goharzadeh et al. $(2006,2007)^{20,21}$ & Fluid Mechanics \\
\hline Okcay and Oztekin $(2008)^{22}$ & Fluid Mechanics \\
\hline Shih et al. $(1999)^{23}$ & Fluid Mechanics \\
\hline Medina et al. $(2012)^{24}$ & Fluid Mechanics \\
\hline Anderson and Losaw $(2002)^{25}$ & Fluid Mechanics \\
\hline Santa Cruz et al $(2013)^{26}$ & Solid Mechanics \\
\hline Lava et al. $(2014)^{27}$ & Solid Mechanics \\
\hline Shiau and Hobson $(2011)^{28}$ & Soil Mechanics \\
\hline
\end{tabular}

Figure 3 and Table 1 provide strong evidence that DIC is quickly becoming a well-established tool for civil engineering research, including within the sub-discipline of geotechnical engineering. The low number of published applications of DIC to soil mechanics suggests that the use of DIC in geotechnical engineering education is still very rare. Developing DIC as an effective visualization tool for soil displacement not only has the immediate benefit of enhancing a student's understanding of soil mechanics, it also addresses ABET Student Outcome (k) by exposing students to the advanced research tools they may encounter in graduate school. Therefore, there is a significant need and opportunity to develop practical and engaging teaching activities that utilize DIC within undergraduate geotechnical engineering subjects, including the concepts of bearing capacity and lateral earth pressure.

\section{Overview of lateral earth pressure and bearing capacity theories}

The earth pressure theory proposed by William Rankine $(1857)^{29}$ and the lower bound bearing capacity theory proposed by Karl Terzaghi $(1943)^{30}$ are commonly presented in an introductory course. These theories, along with other theories of bearing capacity and lateral earth pressure, are described in many geotechnical engineering textbooks ${ }^{31,32}$, so only a brief overview is provided here. Both theories assume that shear stresses in the soil required for equilibrium along an assumed failure surface are equal to the fully mobilized shear strength of the soil. Furthermore, both theories assume plane strain conditions. Earth pressure theory is used to estimate the normal and shear stresses exerted by soil on a vertical or near vertical structure. For 
a vertical structure with a horizontal soil backfill surface, Rankine earth pressure theory assumes that no shear stress is exerted on the structure by the soil. There are two limiting cases of earth pressure, the active condition and the passive condition, which are determined using the MohrCoulomb failure criterion assuming that the major and minor principle stresses are oriented parallel and normal to the soil backfill surface. The convention in geotechnical engineering is to assign a positive sign to compressive stresses. The active condition is reached when the minor principle stress is reduced until shear failure occurs under constant major principle stress. A typical example of this situation occurs when an initially-vertical retaining wall is allowed to slide and/or rotate slightly away from the backfill. As the wall moves, the horizontal stress is reduced while the vertical stress remains constant until the limiting active condition is reached. The passive condition is reached when the major principle stress is increased until shear failure occurs under constant minor principle stress. A typical example of this situation occurs when an initially-vertical anchor block embedded in soil is pulled and/or rotated toward the backfill. As the anchor block moves, the horizontal stress is increased while the vertical stress remains constant until the limiting passive condition is reached.

Bearing capacity theory is used to estimate the maximum downward-acting pressure that can be applied to a soil. The applied pressure, called the bearing pressure, is often produced by a foundation load, embankment, or material stockpile.

Both theories assume idealized failure surfaces for estimating the failure loads. Figures 4 and 5 illustrate the failure surfaces assumed by Rankine and Terzaghi for a soil adhering to a MohrCoulomb failure criterion with known values of the internal friction angle, $\phi$, and cohesion, $c$, shear strength parameters. For the level backfill case, Rankine theory assumes a planar failure surface that is inclined at an angle of $45+\phi / 2$ above horizontal for the active condition and $45-\phi / 2$ for the passive condition. The assumed failure surface for bearing capacity analysis is more complex. Directly beneath the bearing area, the soil is assumed to reach a limiting active condition with respect to the horizontal confining stress and the failure surface is characterized by a planar surface inclined $45+\phi / 2$ above horizontal. The horizontal confinement provided to the soil beneath the bearing area is limited by the passive condition in the soil beyond the lateral extents of the bearing area. The failure surface in this region is characterized by a planar surface inclined $45-\phi / 2$ above horizontal. Between active and passive zones, there is a transition zone called the Prandtl zone in which the failure surface follows the shape of a log spiral. The active, Prandtl, and passive zones are respectively labeled A, B, and C in Figure 5. 


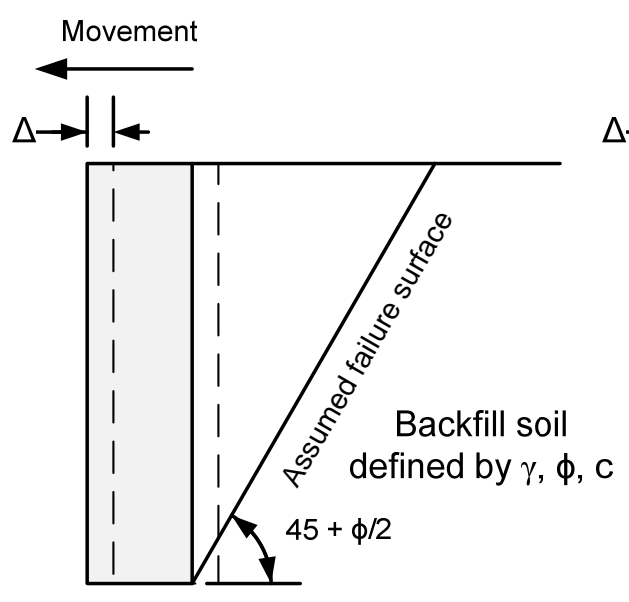

(a) Active condition

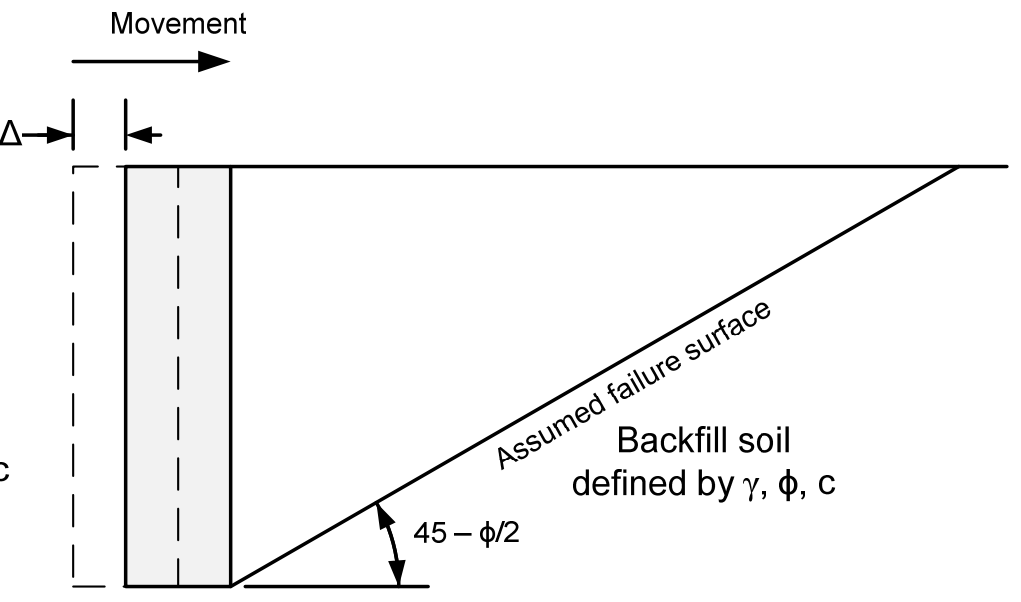

(b) Passive condition

Figure 4: Limiting earth pressure conditions according to Rankine theory

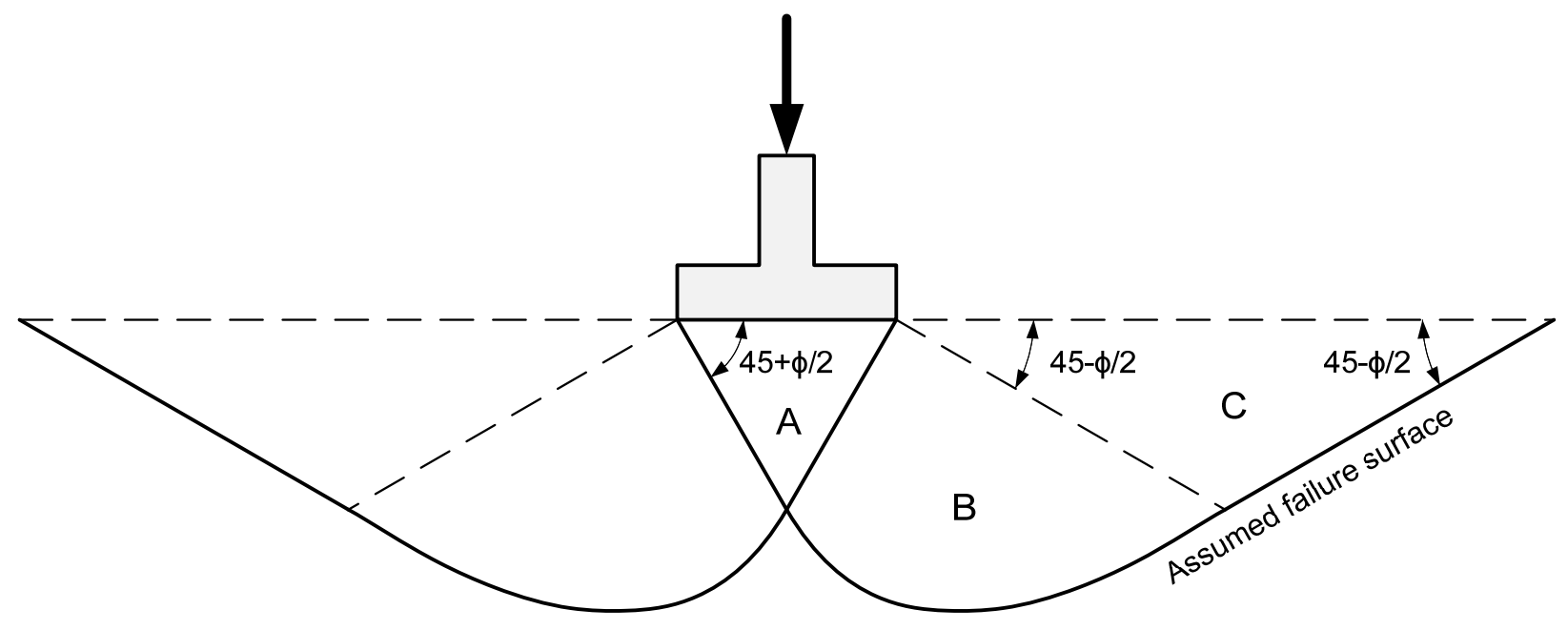

Foundation soil defined by $\gamma, \phi, \mathrm{c}$

Figure 5: Bearing capacity failure mechanism used by Terzaghi $(1943)^{30}$

Neither theory directly considers the soil displacements that accompany the failure loads. In conventional geotechnical practice, it is typical for deformations or settlements to be evaluated separately using simple closed-form analytical solutions based on elasticity ${ }^{33}$. Numerical simulation can also be applied to estimate soil displacements. Since soils are nonlinear and often anisotropic materials consisting of a combination of solid, liquid, and gas phases; the selection of an appropriate constitutive model requires an appreciation of soil mechanics, the effort required to estimate values for the model parameters, as well as the goals of the deformation analysis ${ }^{1,34}$. 


\section{Equipment, Materials, and Software}

\section{Soil box}

A soil box with interior dimensions of 16 in. $x 16$ in. $x 3$ in. was fabricated from 0.5 in. thick aluminum plates. The face of the box is made from clear 0.5 in. thick tempered glass. The interior dimensions of the box were selected to minimize boundary effects from the side walls, while maintaining portability for classroom use. It is acknowledged that boundary effects from the side walls exist and that only an approximate plane strain condition is created by the aluminum back panel and glass front panel. However, these limitations are deemed acceptable for the intended use of the apparatus as an educational tool. The sand is loaded by a hydraulically actuated aluminum block with a 3 inch $\mathrm{x} 3$ inch cross section. The loading system may be attached to the top of the soil box, as shown in Figure 6, or to the upper left side of the box, as shown in Figure 7. The top panel of the box is removable for horizontal testing and to allow it to be filled with sand. When performing vertical tests, there is a 3 in. square aluminum plug that bolts to the outside of the left panel to create a flush fit with the inner left side wall. The loading block is moved using a double-acting hydraulic cylinder with a $1.5 \mathrm{in}$. bore and $3 \mathrm{in}$. stroke. The hydraulic cylinder is actuated in the desired direction using a hand-operated pump and a 4-way motor detent valve. A shallow recess was milled into the front face of the loading block. The recessed area is painted white and speckled so the displacement of the loading block can be measured by DIC. The hydraulic fluid pressure is measured on the high-pressure side of the 4way motor detent valve using a digital gauge to obtain the relative magnitude of the load on the block.

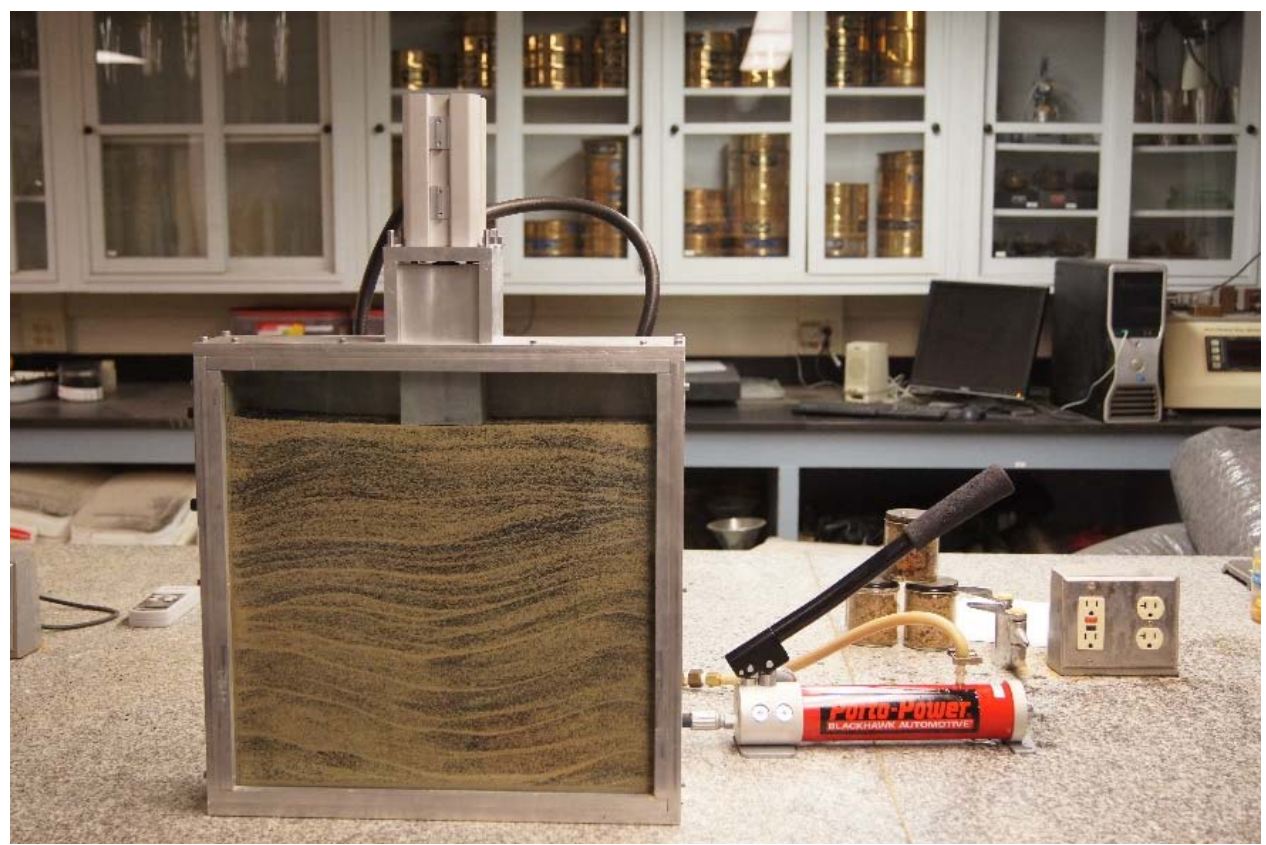

Figure 6: Soil box configured for vertical displacement of the aluminum block 


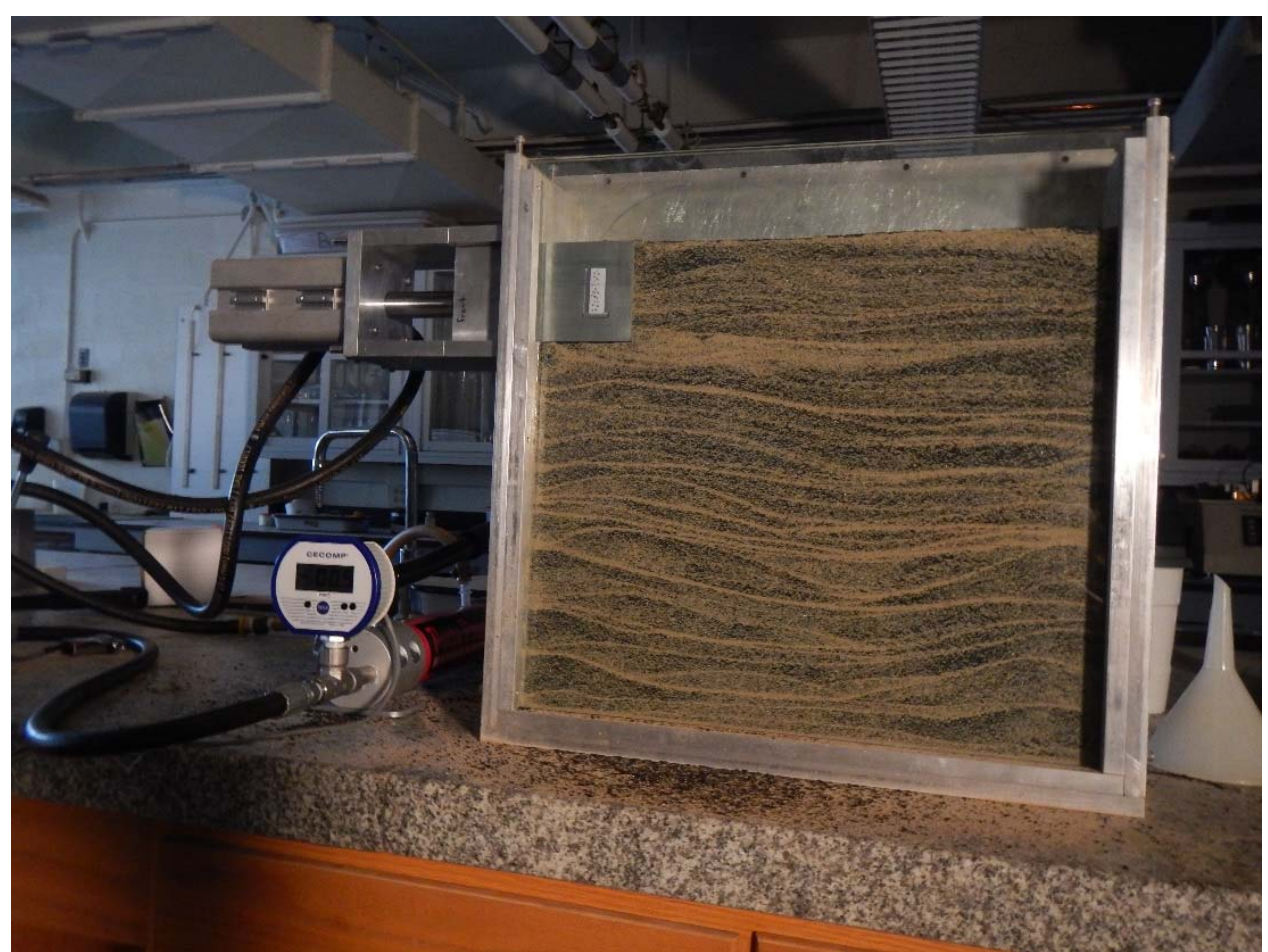

Figure 7: Soil box configured for horizontal displacement of the aluminum block

\section{Sand}

The sand used in the experiments consists of two components: a poorly-graded manufactured sand having a light brown color and a coal slag blasting abrasive having a black color. The sand components are mixed together in an approximate ratio of $1: 1$ by weight. The gradation curves for the individual components and combined material is shown in Figure 8. The box is filled using the technique of air pluviation by maintaining an approximately constant free-fall height and deposition rate. This type of approach helps to reduce spatial variation in sample density.

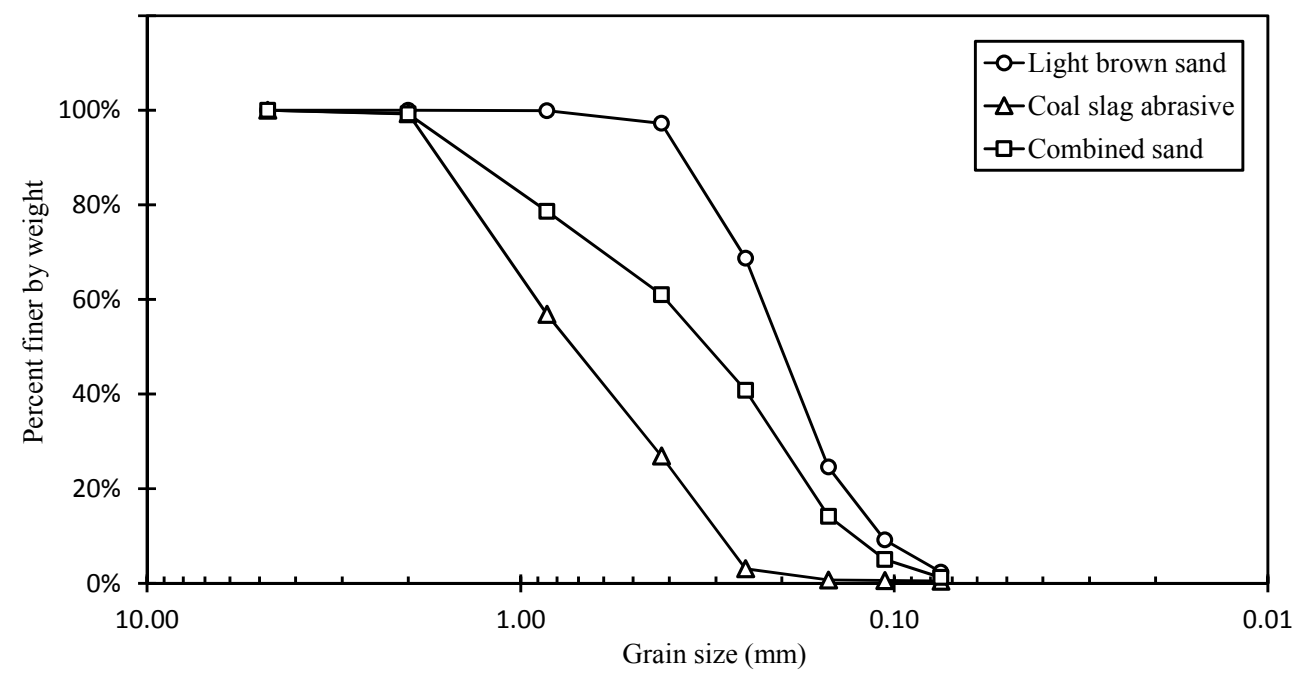

Figure 8: Gradation curves for light brown sand, coal slag abrasive, and combined material 


\section{DIC equipment and software}

The experimental setup is shown in Figure 9. The DIC system uses a Pulnix TM1020 CCD camera with $1008 \times 1018$ pixels. The lens is a 35-70mm, f3.3-4.5, Nikon lens. The camera was positioned perpendicular to the glass face of the soil box. Indirect lighting was produced using a Cool-Lux Softlight. The lighting was placed approximately $45^{\circ}$ off axis from the camera to reduce glare. The image acquisition and DIC software were developed in-house and are two separate programs.

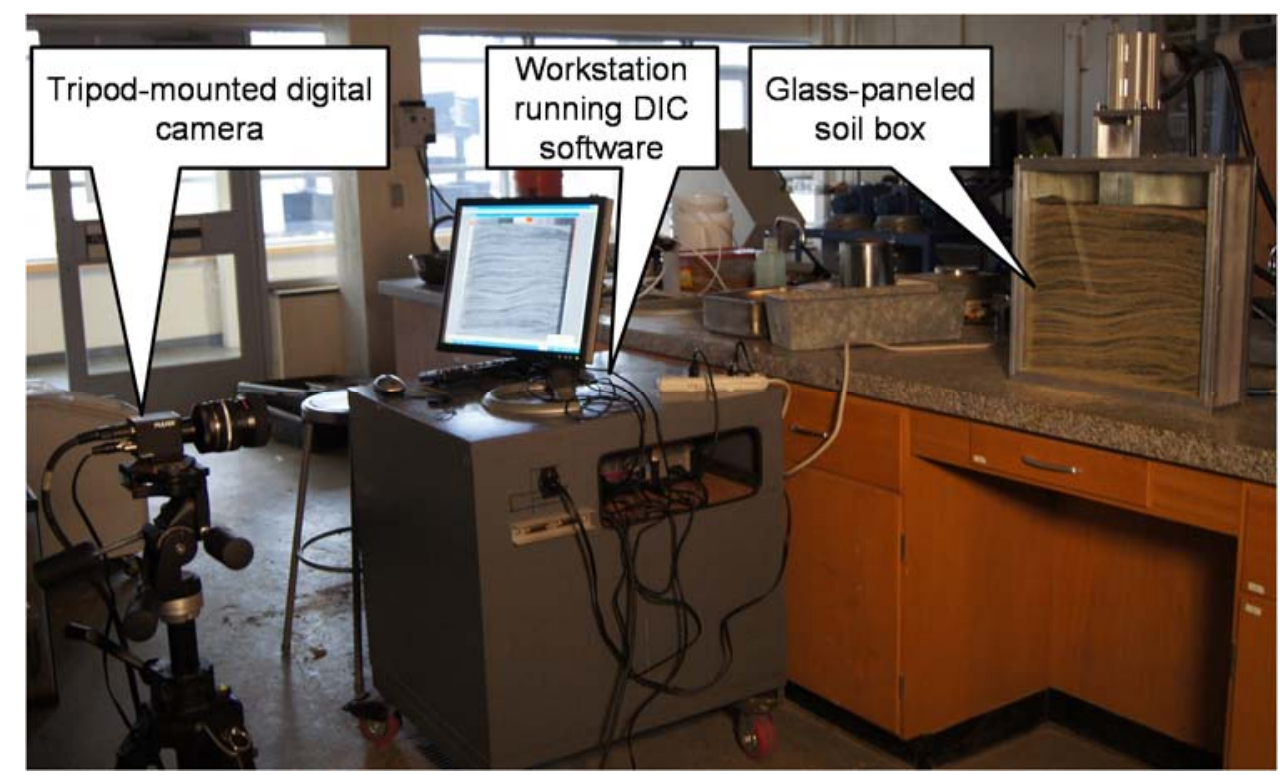

Figure 9: Set up for imaging of the soil box

\section{Initial results}

An initial series of tests were performed to confirm that the equipment, materials, and software are capable of capturing the movement of soil for both vertical displacement and horizontal displacement configurations.

Figure 10 shows the results of a test performed by pushing the aluminum block horizontally into the soil mass, producing the passive earth pressure condition. The portions of the soil experiencing horizontal displacement (top figure) and vertical displacement (bottom figure) are clearly visible. The colored patch that appears on the aluminum block indicates the displacement of the block. The observed boundary of significant soil movements appears to agree reasonably well with the planar failure surface assumed by Rankine's earth pressure theory. Some curvature in the contours of soil displacement is present, particularly in the case of vertical soil movement. This finding suggests that the test equipment and software is capable of visualizing the impact of wall friction on soil movements. Note that displacements are expressed in pixels. It is a simple operation to apply a conversion between pixels and length units.

Figure 11 shows the results of a test performed by pushing the aluminum block vertically down into the soil mass, producing a bearing capacity failure condition. The contours of differential 
horizontal movement shown in Figure 11 highlight portions of the soil mass experiencing high shear strains. The portions of the soil mass with elevated differential soil movement agree reasonably well with the shearing surfaces assumed by Terzaghi's bearing capacity theory. It is apparent from the test results that the soil movements extend to the boundaries of the tank.

Reducing the width of the aluminum block for subsequent bearing capacity tests will reduce the impact of the wall boundaries.

The results of these tests confirm that DIC technology can be applied to visualize soil movements. The equipment, software, and test procedures will be refined based on the lessons learned. The final apparatus and software will be described in a follow-up paper.

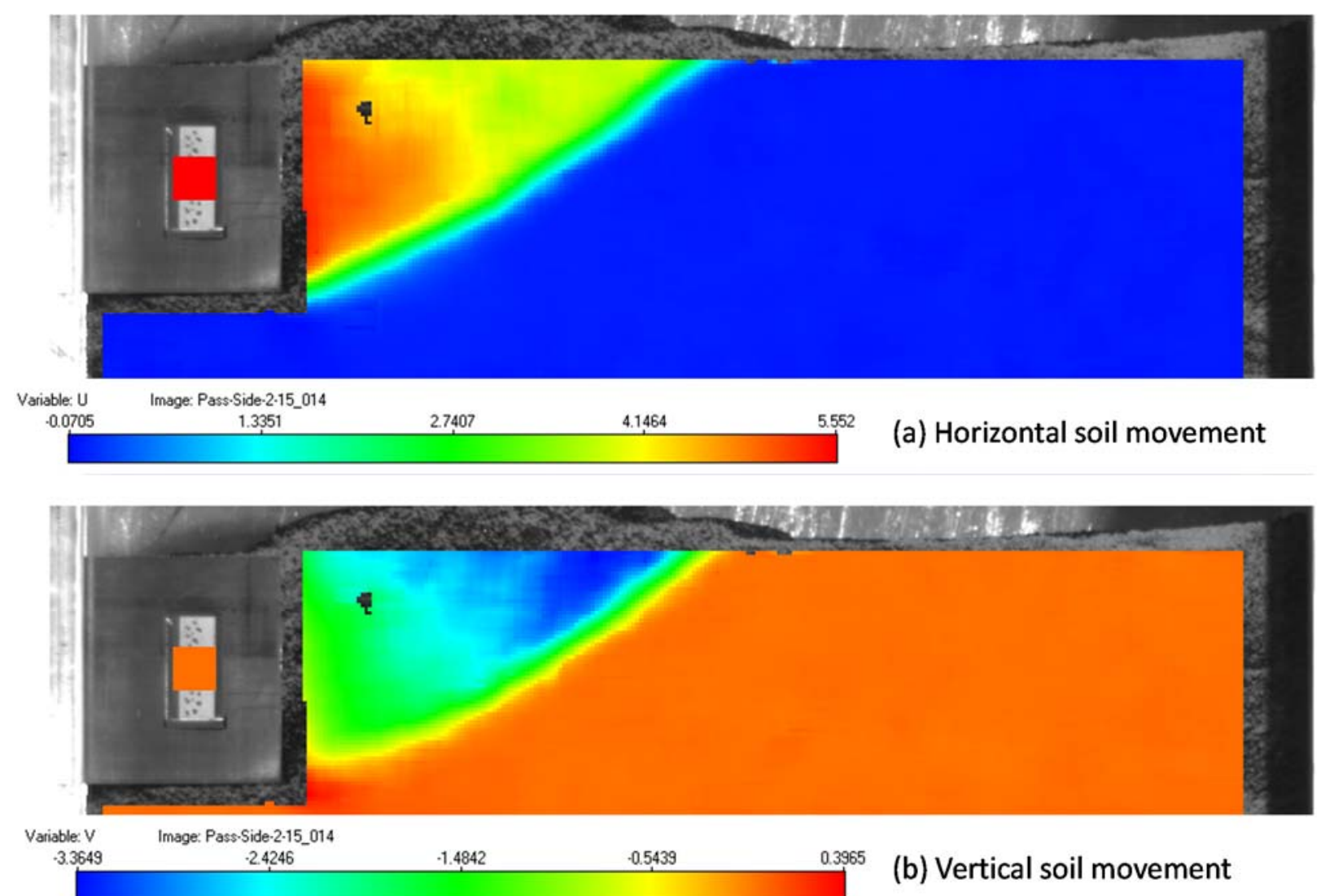

Figure 10: Horizontal and vertical soil movements for passive movement of the aluminum block. Displacements are expressed in pixels. Downward vertical movement is positive. 

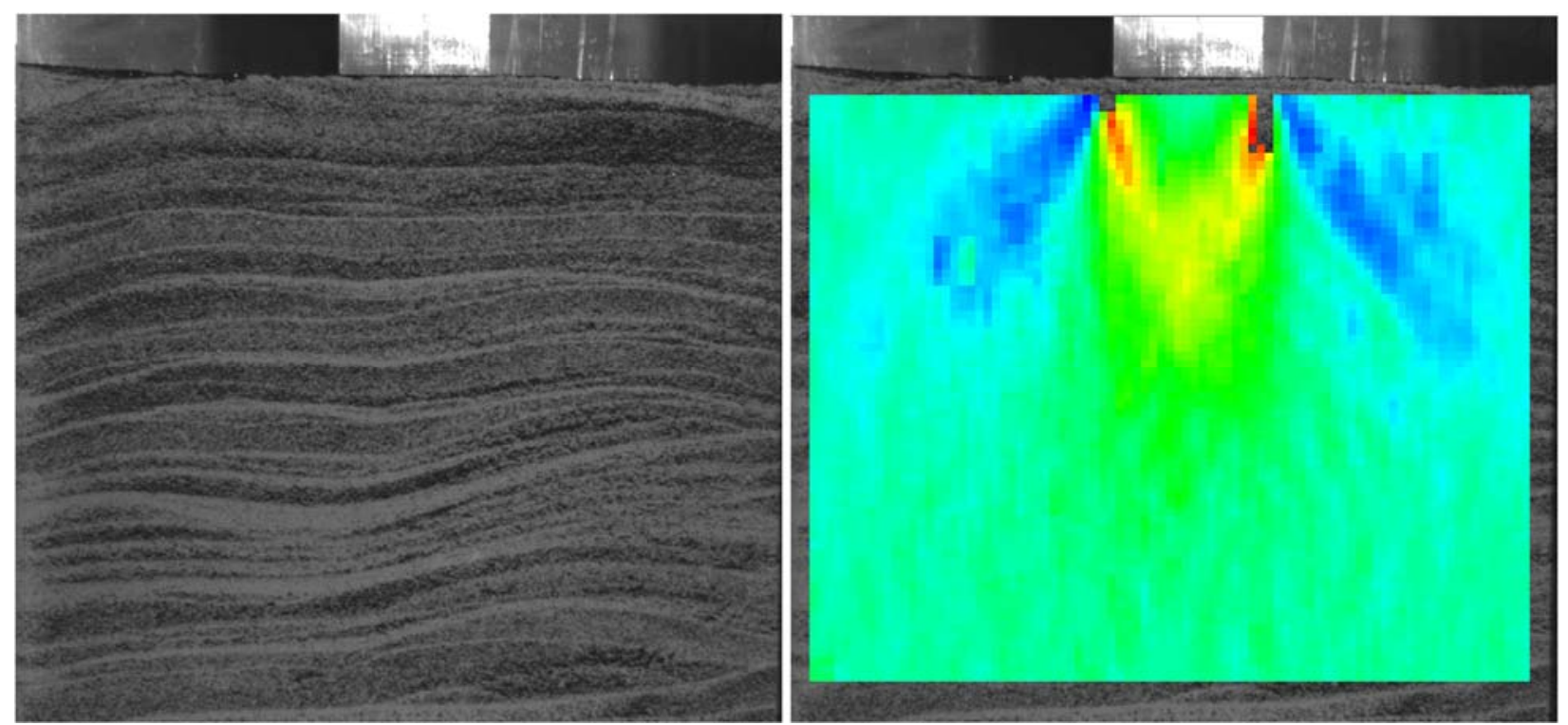

Figure 11: Differential horizontal soil movement, du/dx, due to application of bearing pressure

\section{Proposed teaching activities}

The teaching activities outlined below will be integrated into the existing introductory geotechnical engineering course taught at Lafayette College. As the course is currently organized, bearing capacity is covered right after lateral earth pressures. A follow-up paper will describe the details of each activity, intended learning outcomes, and measured impacts.

\section{Earth pressure activity}

The earth pressure activity aims to:

- Illustrate that relatively small wall displacements away from the backfill are required to reach a minimum earth pressure condition (active condition)

- Illustrate that larger wall displacements toward the backfill are required to reach a maximum earth pressure condition (passive condition).

- Illustrate that lateral movement of a wall produces vertical movement of the backfill.

- Allow students to judge how well the idealized failure surfaces coincide with the locations in the soil mass exhibiting high shear strains and explain how wall friction impacts the distribution of soil displacements.

This activity can be performed once by moving the aluminum block away from the soil to investigate the active earth pressure condition and once by moving the aluminum block toward the soil to investigate the passive earth pressure condition. The three components of the activity are: (1) observe the contours of soil displacement obtained from the DIC-derived measurements, (2) plot the relationship between the jacking pressure and the movement of the aluminum block for the passive case, and (3) plot the relationship between the horizontal movement of the aluminum block and average vertical movement of the soil surface at a selected location in front of the block. Figure 12 shows what students might see for a particular increment of block 
movement. The relationships between block movement and jacking pressure for the passive tests can be plotted in a manner similar to what is shown in Figure 1. If the unit weight and friction angle of the sand is estimated using laboratory tests, the slope of the assumed planar failure surface and the failure load estimated by Rankine theory can be compared to the observed contours of displacement. This exercise provides an opportunity to discuss the potential errors introduced in the estimate of the friction angle by differences in void ratio, confining stress, and boundary conditions between the soil box and the method used to evaluate the friction angle (e.g. vacuum triaxial test). The strong curvature observed in the contours of soil displacement for the passive case illustrate the contribution of friction between the aluminum block and the soil. If this activity is performed as part of an upper-level geotechnical elective course, the observed contours of soil displacement provide a good way introduce log spiral earth pressure theory ${ }^{35}$. Performing a series of passive tests, with each test using an aluminum block having a different textured surface, could be used to demonstrate the impact of wall friction on the development of passive resistance. Finally, additional processing of the DIC-derived measurements of soil displacement can be used to show that slip surfaces within sand (and other soils) are actually bands of soil with non-zero thickness that have undergone a progressive accumulation of shear strain.

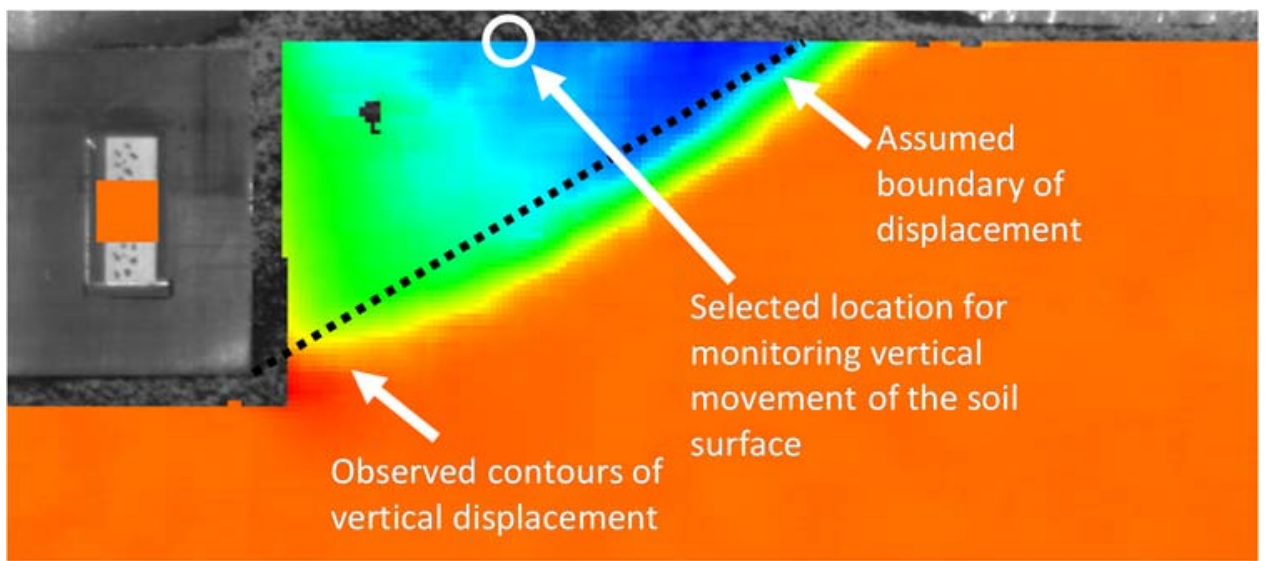

Figure 12: Observations of vertical soil movement for earth pressure activity

Bearing capacity activity

The bearing capacity activity aims to:

- Demonstrate that footings on a dense soil foundation tend to exhibit a relatively stiff load-displacement behavior with a distinct peak failure load, while footings on a loose soil foundation tend to exhibit a soft loaddisplacement behavior with a lower, less distinct, failure load.

- Help students be able to distinguish between general bearing capacity failure and punching shear failure.

In this activity, students will observe the relationship among the applied bearing pressure, block displacement, and strains within the soil mass, similar to what is shown in Figure 2. This activity will be inserted into the course schedule as a transition between discussion of lateral earth pressure and bearing capacity. The two components of the activity are: (1) observe the contours of soil displacement obtained from the DIC-derived measurements and (2) plot the relationship 
between the jacking pressure and the downward movement of the aluminum block. The relationships between block movement (settlement) and jacking pressure can be plotted in a manner similar to what is shown in Figure 2. As described above for the earth pressure activity, estimated of the unit weight and friction angle for the sand can be used to generate the assumed shape of the bearing failure surface and the theoretical failure load. Variations of this activity could include performing a series of tests using blocks having different widths, or performing tests using a very loose and compressible material, such as flour or talc, to illustrate punching failure as depicted in Figure 2.

\section{Conclusions}

This paper demonstrates that DIC technology can be applied to visualize soil movements. Initial tests using the soil box, camera hardware, and DIC software were successfully able to capture the distribution of soil movements for both horizontal and vertical displacement of an aluminum block into the soil mass. In both testing cases, the observed distribution of soil movements make sense based on the expected locations of shearing assumed by Terzaghi's bearing capacity theory and Rankine's earth pressure theory. The equipment, software, and test procedures will be further refined based on the outcome of the initial series of tests. A literature review performed as part of this study uncovered a growing number of applications of DIC to civil engineering research, including projects related to geotechnical engineering. There are also many examples of DIC being used as a teaching tool in the undergraduate engineering education. Most of the accounts identified in the literature review describe the use of DIC, and the similar method PIV, to observe the movements of fluids (air and water). Only one account was identified of using image correlation to observe soil movements.

\section{Acknowledgements}

This project is funded by a grant from the Lafayette College Information Technology and Library Faculty Committee. The authors are grateful to Michael Yust for his help in the lab.

\section{References}

1. Lade, P. V. (2005) "Overview of constitutive models for soils." GSP 139 Calibration of Constitutive Models, pp $1-34$.

2. Clough, G.W. and Duncan, J.M. (1971). "Finite element analyses of retaining wall behavior." Journal of Soil Mechanics and Foundations Division, ASCE, Vol. 97, SML2, pp 1657 -1673.

3. DeBeer, EE. and Vesic, A. 1958. "Etude experimental de la capacitie portante du sable sous des foundations directes etablies en surface." Annales des Travaux Publics de Belqique, Vol. 59, No. 3, pp5-58.

4. Sutton, M. A., Orteu, J.-J., Schreier, H. W. (2009) Image Correlation for Shape, Motion and Deformation Measurements: Basic Concepts, Theory and Applications, Springer, New York.

5. Hall, S. A., et al. (2010) "Discrete and continuum analysis of localized deformation in sand using x-ray $\mu \mathrm{CT}$ and volumetric digital image correlation." Géotechnique, Vol. 60, No. 5, pp 315-322.

6. Hall, S. A. (2012) "Full-field displacement/strain measurements and digital image correlation - principles and methods" ALERT Geomaterials Doctoral School 2012, Grenoble, France. 
7. Suleiman, M. T., et al. (2014) "Soil-pile interaction for a small diameter pile embedded in granular soil subjected to passive loading." Journal of Geotechnical and Geoenvironmental Engineering, ASCE. 2014. 140

8. White, D. J., et al. (2003). "Soil deformation measurement using particle image velocimetry (PIV) and photogrammetry.” Géotechnique, Vol. 53, No. 7, pp 619-631.

9. Bhandari, A.R., Powrie, W., Harkness, R.M. (2012). A digital image-based deformation measurement system for triaxial tests." ASTM Geotechnical Testing Journal, Vol. 35, No. 2, pp209-226.

10. Vitone, C., et al. (2013). "Localized deformation in intensely fissured clays studied by 2D digital image correlation.” Acta Geotechnica, Vol. 8, pp.247-263.

11. Dejong, J. T., et al. (2009). "Role of initial state, material properties, and confinement condition on local and global soil-structure interface behavior." Journal of Geotechnical and Geoenvironmental Engineering, ASCE, Vol. 135, No. 11, pp 1646-1660.

12. Divya, P. V., et al. (2014). "Evaluation of tensile strength-strain characteristics of fiber-reinforced soil through laboratory tests." Journal of Materials in Civil Engineering, ASCE, pp 14-23.

13. Lesniewska, D., Wood, D. M. (2009). “Observations of stresses and strains in granular material.” Journal of Materials in Civil Engineering, ASCE, pp 1038-1054.

14. Tian, Y., Gaudin, C., Cassidy, M. J., Randolph, M. F. (2013) "Considerations on the design of keying flap of plate anchors." Journal of Geotechnical and Geoenvironmental Engineering, ASCE, Vol. 139, No. 7, pp 11561164 .

15. Ahmed, M., Iskander, M. (2011). "Analysis of tunneling-induced ground movements using transparent soil models." Journal of Geotechnical and Geoenvironmental Engineering, ASCE pp 525-535.

16. Daehne, A., Corsini, A. (2013). "Kinematics of active earthflows revealed by digital image correlation and DEM subtraction techniques applied to multi-temporal LiDAR data." Earth Surface Processes and Landforms, 38 , pp 640-654.

17. Papadopoulos, G. (2003). "A PIV-based educational facility for hydraulic research.” International Association for Hydraulic Research Congress, Salonika, Greece, pp 201-209.

18. Ring, B. P., Lemley, E. C. (2014). "Design and implementation of a low cost particle image velocimetry system for undergraduate research and education." American Society for Engineering Education.

19. Brower, T. I. (2011). "Going with the flow in a service learning project." AC 2011-751, American Society for Engineering Education.

20. Goharzadeh, A., et al. (2006). "A proposed particle image velocimetry (PIV) system for instructional purposes in a modern mechanical engineering undergraduate laboratory program." 2006-1293, American Society for Engineering Education.

21. Goharzadeh, A., et al. (2007). "Innovative fluid mechanics experiments for modern mechanical engineering program." AC 2007-987, American Society for Engineering Education.

22. Okcay, M., Uygar, B. (2008). "Educational particle image velocimetry interactive experiment suites." American Society for Engineering Education.

23. Shih, C, et al. (1999). "Integration of optical diagnostics techniques into the teaching of thermal and fluid sciences laboratory course.” American Society for Engineering Education. 
24. Medina, R., et al. (2012). "On the implementation of open source CFD system to flow visualization in fluid mechanics.” AC 2012-5482, American Society for Engineering Education.

25. Anderson, A. M., Losaw, J. (2002). "Using race car aerodynamics to teach mechanical engineering students about fluid mechanics." American Society for Engineering Education Annual Conference and Exposition,

26. Santa Cruz, J. et al. (2013). "In-situ strain localization measurements of shape memory alloy actuators during a research experience for undergraduates program." American Society for Engineering Education.

27. Lava, P., et al. (2014). "Digital image correlation in the classroom: determining stress concentration factors with webcams." Experimental Techniques, Vol 38, pp 72-80.

28. Shiau, J. S., Hobson, M. A. (2011). "Teaching earth pressure theory using physical models: an example in civil engineering." IETEC, Malaysia

29. Rankine, W.J.M. (1857). "On the stability of loose earth.” Philosophical Transactions of the Royal Society, Vol. 147 , London.

30. Terzaghi, K. (1943). Theoretical Soil Mechanics, John Wiley, New York.

31. Coduto, D. P., Yeung, W.R., and Kitch, W.A. (2011). Geotechnical Engineering: Principles and Practices, $2^{\text {nd }}$ Edition, Pearson, Upper Saddle River, New Jersey.

32. Briaud, J.-L. (2013). Geotechnical Engineering: Unsaturated and Saturated Soils, John Wiley \& Sons, Hoboken, New Jersey.

33. Davis, E. H., Poulos, H. G. (1974). Elastic Solutions for Soil and Rock mechanics, John Wiley and Sons, New York.

34. Duncan, J. M. (1994). "The role of advanced constitutive relations in practical applications." XIII ICSMFE, New Delhi, India

35. Duncan, J. M., Mokwa, R. L. (2001). "Passive earth pressures: theories and tests." Journal of Geotechnical and Geoenvironmental Engineering, Vol 127, No. 3, pp 248-257. 